\title{
The following abstracts were presented as posters at the 2011 NEI Global Psychopharmacology Congress
}

\section{DISCLAIMER}

The material presented in this section contains the abstracts submitted as part of the poster session at the 2011 NEI Global Psychopharmacology Congress, Colorado Springs, CO, USA, 10-13 November 2011.

The abstracts have not been peer reviewed as part of the standard processes of CNS Spectrums and may contain promotional content that does not represent the views or policies of the journal or publisher. The abstracts are not approved for continuing education credit. Poster content and the views expressed therein are those of the presenting entity and not the Editors of CNS Spectrums, Cambridge University Press or of the Neuroscience Education Institute. Authors have not provided standard disclosure forms as part of their submission, although these would have been evident at the time of the poster presentation. 


\title{
Abstracts
}

The following abstracts were presented as posters at the 2011 NEI Global Psychopharmacology Congress.

\section{PS-101}

\section{Maintenance Electroconvulsive Therapy in the Treatment of Parkinson's Disease}

Robert B. Shulman, MD

\begin{abstract}
Parkinson's disease, a neurodegenerative disorder affects over 1\% of the population over 60 years of age. Despite many new pharmacologic agents, Parkinson's disease remains a progressively deteriorating illness often complicated by psychiatric morbidity including depression, anxiety and dementia. Non-pharmacologic treatments have been employed in Parkinson's disease including pallidotomy and most recently deep brain stimulation.
\end{abstract}

Electroconvulsive therapy (ECT) was noted to provide benefit for Parkinson's disease as early as 1947. There have been numerous reports on this subject published in the literature in the intervening years, predominantly regarding Parkinson's disease with co-morbid psychiatric illness, usually depression. There have been few reports of ECT specifically for the movement disorder symptoms of Parkinson's disease and still fewer articles reporting on the use of maintenance ECT in this condition.

The author reported one such case, published in Geriatrics November 2003. We now present a review of the worldwide literature through a MEDLINE search on the use of maintenance ECT in Parkinson's disease. Parameters of study include whether the primary purpose of ECT was for the movement disorder of Parkinson's disease or for psychiatric comorbidity. Each case was examined for frequency and duration of treatment and outcome. Secondary measures include an assessment of function, whether concomitant medications could be reduced, an assessment of side effects from ECT versus beneficial diminishing of medication side effects if there was a reduction of pharmacologic agents, and the global impression of each report's author on the effects of maintenance ECT in Parkinson's disease.

PS-102

Psychiatry Resident/Fellow Initiated and Designed Bipolar Module Project as a Part of the Psychopharmacology Curriculum

Nirupama Natarajan, MD

\begin{abstract}
Teaching psychopharmacology requires the effective transfer of an ever-changing information base to maximize effectiveness, adherence and satisfaction. Resident training in Psychopharmacology may be advanced through improvements in teaching neuroscience and developing up-to-date core curricula. At the 2006 American Association of Directors of Psychiatric Residency Training (AADPRT) annual meeting, an ad hoc committee was formed including individuals from the American Society of Clinical Psychopharmacology (ASCP) curriculum committee to help make the ASCP's Psychopharmacology Curriculum more 'resident-friendly". A workshop presented at the 2007 AADPRT meeting introduced the multifaceted schizophrenia module. As a next step the ASCP formed the Committee on Residency and Fellowship, comprised of AADPRT and ASCP leadership and psychiatry trainees. The Committee received nominations from psychiatry residency training directors nationwide, selected 15 members and formed 2 sub-groups in order to work on the development of multi-model training modules for bipolar disorder and depression. This presentation highlights the progress of the bipolar curriculum group.
\end{abstract}

Methodology: Monthly conference calls have been held since August 2008. The workgroup performed a review of published ABPN, APA, AADPRT, and ACGME core competencies and practice guidelines to delineate the scope of the psychopharmacology curriculum to be developed. Each resident was assigned a specific topic to research and develop. A Google group was set up for residents to update their work on the module.

Content: The Bipolar group has developed a list of topics including Epidemiology, Co-morbidities (including ADHD, Substance Use Disorders and Borderline Personality), Bipolar Depression, Atypical Antipsychotics \& Mood Stabilizers, Psychosocial Aspects of Treatment. Twelve mini-modules were chosen to make up the Bipolar teaching Module, each of which could be used as free-standing sessions or as one comprehensive curriculum. The core of each module was a Power Point presentation. Corresponding multi-modal learning activities stemmed from each mini-module. Problem and group-based learning and alternative teaching exercises were developed for each mini module to reinforce didactic learning objectives and extend learning beyond the scope of the slide set. A variety of teaching modalities such as Jeopardy-type game, podcasts, case presentations and team based learning exercises were used.

Importance: The bipolar module is an innovative tool for teaching psychopharmacology which enables psychiatric trainees and other psychiatrists to master a large volume of information. A psychiatry resident/fellow designed 
Bipolar Module was designed to suit the needs of individual Residency Programs and improve psychopharmacology teaching by emphasizing Multi-Modal learning. The Module is scheduled to undergo field testing at Psychiatry Residency Programs to test feasibility and effectiveness.

\title{
PS-N01
}

Response to kainic acid and cell loss in the 3xTg-AD mouse subiculum: Effect of strain background Debbi Ann Morrissette, Ph.D; Frank M. LaFerla, PhD

\begin{abstract}
Alzheimer's disease (AD)is a devastating neurodegenerative disease characterized by beta-amyloid plaques, aggregates of tau into neurofibrillary tangles, and neuronal cell loss. Several transgenic mouse models of AD recapitulate the plaque or tangle pathology7, however, the cell loss aspect has proven more elusive. Although there is still some debate over the ultimate cause of cell loss in AD, evidence supports the idea that beta-amyloid may act as an excitotoxic agent that leads to disruption of calcium homeostasis (much like glutamate). The lack of cell loss in transgenic AD mice may stem from the fact that mouse background strain has a profound effect on the susceptibility of an animal to excitotoxic injury. Although some mouse strains (e.g. FVB/N) exhibit cell loss in response to treatment with excitotoxic agents such as kainic acid (KA), other strains (e.g. C57BL/6) are resistant to the same insults. This discrepancy between susceptible and resistant mice with regards to excitotoxin-induced cell loss occurs despite similar seizure activity in response to excitotoxic agents. It has been shown that cells from susceptible mouse strains are impaired in their ability to effectively prevent and/or buffer excitotoxin-induced elevations in calcium.
\end{abstract}

Our laboratory created a triple transgenic mouse mode of AD (3xTg-AD) in a mixed C57BL6/129SvJ background. The 3xTg-AD mice harbor mutant transgenes encoding amyloid precursor protein $\left(\mathrm{APP}_{\mathrm{SWE}}\right), \mathrm{Tau}_{\mathrm{P} 301 \mathrm{~L}}$, and $\mathrm{PS} 1_{\mathrm{M} 146 \mathrm{~V}}$ and develop both plaques and tangles in an age-dependent manner. In an effort to determine the effect of strain background on AD-like pathology, we are generated certified congenic 3xTg-AD mice on either an inbred FVB (susceptible) or C57BL/6 (resistant) background. We report here data obtained from KA treatment of 7 generations of treatment of 3xTg-AD X FVB backcrosses (98.4\% congenic). Also included are the results from a stereological assessment of cell number in the subiculum of 3xTg-QAD mice on the original 3xTg/ $129 \mathrm{SvJ}$ background. In addition, we describe the effects of the FVB background strain on AD-like pathology in the 3xTg-AD model and provide evidence linking intraneuronal beta-amyloid with neurodegeneration.

\section{PS-103}

Assessment of the effects of AZD3480 on cognitive function in patients with schizophrenia Adonis Sfera, MD

\begin{abstract}
AZD3480 is a selective agonist of alpha4beta2 central neuronal nicotinic receptors (NNRs). This study investigated its effects on cognition, relative to placebo, in 440 patients with stable schizophrenia who were taking a single atypical antipsychotic medication and who were active cigarette smokers. Mean age was 41 (range 19 to 55 ) years and the majority of patients (88\%) had a diagnosis of paranoid schizophrenia. Patients were randomized to one of 3 doses of AZD3480: $5 \mathrm{mg}, 20 \mathrm{mg}$, and 35/100 mg (depending on CYP2D6 metabolic status), or to placebo. Treatment was given once daily for 12 weeks. The primary outcome measure was change in cognitive function from baseline to Week 12, as measured by IntegNeuro computerized test battery of cognitive function scores. Secondary outcome measures included assessment of functional capacity (University of California at San Diego Performance Based Skills Assessment [UPSA2]) and adaptive function (Social Functioning Scale [SFS]). AZD3480 failed to improve cognition relative to placebo in this population of patients or in sub-populations defined by disposition, metabolic status, antipsychotic treatment, age, age of illness onset, and sex. Likewise, no improvement relative to placebo was observed in either the SFS measure of adaptive functioning or the UPSA2 measure of functional capacity. AZD3480 was generally well tolerated in the population studied.
\end{abstract}

\section{PS-104}

Effects of Sapropterin Dihydrochloride on Neuropsychiatric Symptoms in PKU Subjects-Clinical Study Design Stephen M. Stahl, MD, PhD; Imperiale M; Walling SE; Lang W.

\footnotetext{
Abstract: Phenylketonuria (PKU) results from deficient phenylalanine hydroxylase activity leading to toxic phenylalanine (Phe) levels manifested, among other conditions, as intellectual disability, neuropsychiatric symptoms and abnormal behavior. Fortunately, universal newborn screening permits early identification of infants with PKU and dietary treatment prevents the more serious consequences. Despite dietary treatment, however, many children, adolescents and adults with PKU experience cognitive deficits and neuropsychiatric symptoms not unlike the same symptoms experienced in patients with ADHD (Attention deficit hyperactivity disorder). Clinical observations already suggest that treatment with sapropterin dihydrochloride (sapropterin) may result in reduced Phe levels and improved neuropsychiatric symptoms.
} 
This study will evaluate the therapeutic effects of sapropterin on Phe levels and global functioning and the symptoms of attention deficit hyperactivity disorder (ADHD), depression and anxiety in subjects with PKU. The durability of sapropterin treatment on ADHD, anxiety, depression and global function will be assessed through 26 weeks.

This is a double-blind, placebo-controlled, randomized study. Approximately 200 male and female subjects, $\geqslant 12$ years old diagnosed with PKU will be randomized 1:1 to receive either $20 \mathrm{mg} / \mathrm{kg} /$ day sapropterin or placebo for 13-weeks of blinded treatment then receive $20 \mathrm{mg} / \mathrm{kg}$ /day of open-label sapropterin for an additional 13 weeks. Symptoms of ADHD will be evaluated using the Attention-Deficit Hyperactivity Disorder Rating Scale (ADHD RS) and the Adult ADHD Self-Report Scale (ASRS) in subjects 12-17 years old and $\geqslant 18$ years old, respectively. The Hamilton Anxiety (HAM-A) and Hamilton Depression (HAM-D) Rating Scales will provide measures of depression and anxiety. The Clinical Global Impression (CGI-S and CGI-I) scales will assess behavior and function.

Subjects will be stratified by symptoms of ADHD, age and use of ADHD medication. Subjects will undergo assessment of ADHD RS/ASRS, HAM-A, HAM-D, CGI-S and CGI-I at screening and at weeks 4, 8, 13, and 26. Phe levels will be obtained weekly during the first 4 weeks of treatment and during the first 4 weeks of open-label sapropterin treatment to determine Phe level reduction (defined as a mean Phe level decrease $\geqslant 20 \%$ after 4 weeks of treatment). Data from subjects with or without Phe level reduction will be analyzed independently. Primary endpoint analyses will evaluate changes in ADHD RS/ASRS from baseline to week 13 using analysis of covariance, and the proportion of subjects with CGI-I scale rating of 1 or 2 by chi-square test to compare the treatment effect between sapropterin and placebo treated subjects.

The safety of sapropterin treatment to improve symptoms of ADHD, anxiety, and depression in adolescents and adults with PKU will be evaluated by assessing adverse events, laboratory test results, vital signs, and physical examination findings.

PS-N02

Stereological quantification of neurons in 3xTg-AD mice

Debbi Ann Morrissette, PhD; Frank M. LaFerla, PhD

Abstract: Alzheimer disease (AD) is a devastating neurodegenerative disease characterized by beta-amyloid plaques, aggregates of tau into neurofibrillary tangles, and neuronal cell loss. Several transgenic mouse models of AD recapitulate the plaque or tangle pathology, however, modeling the profound loss of neurons seen in the human condition has proven to be somewhat challenging.

The triple transgenic mouse model of $\mathrm{AD}(3 \mathrm{xTg}-\mathrm{AD})$ harbors three mutant transgenes encoding amyloid precursor protein $\left(\mathrm{APP}_{\mathrm{SWE}}\right), \mathrm{Tau}_{\mathrm{P} 301 \mathrm{~L}}$, and $\mathrm{PS}_{\mathrm{M} 146 \mathrm{~V}}$. Although the age-dependent development of both plaques and tangles in these mice has been well-characterized, this represents the first stereologic quantification of neuronal cell number in the 3xTg-AD mice.

\section{PS-105}

Can low dose Abilify, Geodon, Saphris and Latuda stabilize mood in a population of outpatient bipolar spectrum psychiatric patients and allow for a dose reduction of mood stabilizers to improve cognition?

David R. Torres, MD

Method: Bipolar disorders are common recurrent and disabling psychiatric illnesses. The standard treatments for bipolar disorder are Lithium, Depakote and Tegretol. Many people who have co -morbid medical challenges such as closed head injury and exposure to toxic level of alcohol in the past may be sensitive to the atypical antipsychotics at usual recommend doses when used in augmentation of mood stabilizers. The objective of this case study was to evaluate mood stability after low dose atypical antipsychotic augmentation of mood stabilizers in 23 bipolar people using a brief cognition screen and the Hamilton depression scale. People with bipolar one and two disorder who have been stable psychiatrically in an outpatient private practice for 5 to 20 years were used in the study. These people had subtle signs of cognitive dysfunction on average doses of mood stabilizers. Previous attempts to reduce cognitive impairing mood stabilizers were not tolerated as mood instability and depression occurred. Low dose Abilify at $2 \mathrm{mg} \frac{1}{4}$ tablet augmentation enabled dose reductions of lithium, Tegretol and Depakote without mood instability or depression over three years. A clinical scale called the Cycling Mood Rating Scale (CMRS) was developed specifically for the purpose of medication management by evaluating neural circuit functioning.

Results: In my case series, low dose Abilify, Geodon, Saphris and Latuda augmentation appeared to have a modest energizing action and prevented recurrence of symptoms of depression enabling dose reductions of mood stabilizers by about $25 \%$ and stopping Depakote in one case. None of the people in the case series required hospitalization and remained in remission from depression. Many of the people included in the case series were intolerant of the usual FDA standard doses of sedating atypical antipsychotics. 
Quantifiable improvements in cognition were noted in all people as a likely result of reduction of mood stabilizer levels although improvement in attention due to Abilify itself could not be ruled out. A functional improvement in the quality of life was also noted in study subjects.

Conclusions: Off label low dose use of atypical antipsychotics can stabilize moods in people with bipolar spectrum disorders, reduce mood stabilizer dose, prevent recurrent depression and improve cognition.

\title{
PS-106
}

\author{
Using a Referenced-EEG Database to Assist in Predicting Severe Adverse Events and Medication \\ Selection-A Retrospective Chart Review
}

Daniel A. Hoffman, MD; Deb Arrera; Nicole Shadid, MD

Study Objective: A new tool that uses quantitative EEG (QEEG) normative and referenced-EEG (rEEG) sampling databases can assist physicians in determining medication selection as well as prevent severe adverse events. It compares drug-free QEEG features for individual patients to a database of patients with similar EEG patterns and known outcomes after pharmacological interventions. Previous studies have demonstrated similar success. ${ }^{1-7}$

We report on an uncontrolled, retrospective chart review of clinical cases having received a QEEG utilizing the referenced-EEG database (now called PEER Outcome report). This is the result of patients during the period 2003 - mid 2011. The purpose was to determine if PEER Outcome information would improve overall clinical results and patients' quality of life in an outpatient setting. In addition, we hypothesized that the information from the report might help prevent severe adverse events if this data was available before prescribing medications for the non-psychotic psychiatric population.

Methods: The patient population consisted of any non-psychotic diagnosis typically seen in a private outpatient clinical setting that agreed to follow the medication plan suggested by the PEER Outcome report. The option for using the report was offered to patients who could safely washout of medication and desired evidenced-based data to augment treatment decisions. Most patients were treatment resistant.

Subjects were analyzed from the date of medication implementation after the report results were available to the point where the prescriber felt they were at Maximum Medical Improvement (MMI) - the point at which they were felt to be stable and no different medication intervention would offer further improvement. The outpatient clinic included three individual providers who rated patients at each session according to the Clinical Global Improvement (CGI-I) rating scale. Patients filled out a Quality of Life (Q-LES-Q-SF) rating at each appointment (for those patients seen after 2009, when the rating scale was implemented in the clinic). All known prior medications along with known severe side effects were also reviewed.

Conclusions: Current psychotropic medication choice is often based on 'trial and error'. Frequently, we still do not know who will respond to a specific treatment. ${ }^{8-10}$ The results of this retrospective chart review suggests that non-psychotic psychiatric patients in an outpatient clinic, most of whom were treatment resistant, demonstrated significant improvement on a global clinical improvement scale and quality of life questionnaire, reached MMI quickly and with fewer reported incidences of suicidality (Table 3). In addition, $54.5 \%$ of previous medications causing a severe adverse event would have been raised as a caution had the PEER Outcome report been available at the time the drug was prescribed. These results need further prospective studies to demonstrate that the efficiency of treatment has significant consequences to both patient suffering and healthcare costs.

\section{PS-N03}

Alzheimer pathology in the 3xTg/FB mouse model: Role of complement C5

Debbi Ann Morrissette, Ph.D; David Cheng; Frank M. LaFerla, Ph.D.

Abstract: Alzheimer Disease (AD) is an age-dependent degenerative affliction that affects a large portion of the population. The $\mathrm{AD}$ brain harbors accumulations of both amyloid beta $(\mathrm{A} \beta)$ into plaques and accumulation of tau into neurofibrillary tangles (NFT) as well as severe neuronal cell loss. It has been challenging to develop a mouse model of AD that encompasses all of these pathological features but the triple transgenic mouse model of $\mathrm{AD}(3 \times \mathrm{Tg}-\mathrm{AD})$ does develop both $\mathrm{A} \beta$ plaques and NFTs. In the present study, we aimed to determine if the 3xTg-AD mouse also develops neuronal loss similar to that seen in human brain. We also studied the effects of mouse genetic background strain on neuronal cell death in addition to A $\beta$ plaques and NFTs by crossing the 3xTg-AD model (mixed C57BL6/129SvJ strain) onto a strain more susceptible to cell death (FVB/N). After determining if mouse background strain affects AD-like neuropathology, further research could lead to clues as to what genetic differences between mouse strains lead to exacerbation of AD-like pathology. Though mice and humans undoubtedly differ from one another in many aspects, knowledge about the factors that affect the severity and/or progression of AD pathology in mice could lead us to new knowledge about factors that affect severity and progression of AD in humans. Our results indicate that whereas there is no significant neuron loss in the original 3xTg-AD mice, altering the background strain to FVB/N did increase the AD-like pathology. 
However, deficiency in complement protein $\mathrm{C} 5$ in the FVB/N strain abrogated all A $\beta$ plaques and tau pathology as well as neuronal cell loss. These results indicate that modulation of complement may offer a potentially effective treatment for $A D$ victims and also underlines the dramatic impact that genetic variability can have on the progression of AD.

\section{PS-107}

Thyroid Stimulating Hormone as a predictor of Metabolic Syndrome for psychiatric patients being treated with an antipsychotic medication

Salvador Ceniceros, MD; Paul Thomlinson, BA; Matthew Underwood, BS; Victoria Rowden, BA;

Joseph F. Hargus, PhD

Study Objectives: The present study investigated the relationship between TSH and Metabolic Syndrome (MetS) in psychiatric patients treated with an antipsychotic medication.

Method: A total of 117 patients undergoing psychiatric treatment at a community mental health center in Southwest Missouri were included in the study. Retrospective data collection was used to identify patients over the age of 18 who were also receiving treatment with an antipsychotic medication and had both a metabolic and a TSH screening in the 12 months prior to the chart abstraction. Primarily physiological measures were collected including height, weight, body mass index, waist circumference, and blood pressure as well as fasting glucose, triglyceride, cholesterol, and TSH levels. The presence of MetS was identified and compared to TSH levels and other physiological measures. Correlations, discriminant analyses, and a relative operating characteristics (ROC) curve were used to examine the relationship between these TSH levels and MetS.

Results: A statistically significant relationship between TSH levels and presence of MetS, $\chi 2(1)=23.04, p<.001$, was identified; patients who had MetS were significantly more likely to have a TSH level that was out of range. TSH levels correlated with several subcomponents of MetS, including waist circumference $(\mathrm{r}=.320, \mathrm{p}<.001)$, diastolic blood pressure $(\mathrm{r}=.243, \mathrm{p}=.008)$, HDL $(\mathrm{r}=-.265, \mathrm{p}=.004)$, and triglycerides $(\mathrm{r}=.477, \mathrm{p}<.001)$. According to the discriminant analysis, a significant mean difference was observed in TSH levels between cases where MetS was present $(M=4.35, S D=2.39)$ and not present $(M=2.15, \mathrm{SD}=1.79), \mathrm{F}=30.31, \mathrm{p}<.001$. The ROC analysis indicated that using an overall TSH cutoff of 2.54 to predict the presence of MetS yielded the best balance between sensitivity $(76.9 \%)$ and specificity $(75 \%)$.

Conclusions: These results indicate that the relationship between TSH level and MetS is strong enough to allow for TSH to serve as means of screening for the likelihood of MetS in certain clinical populations who may have an increased risk of MetS. Though TSH and MetS are shown here to be associated with one another in this population, the underlying root of this association remains unclear.

Burrell Behavioral Health provided the necessary resources to perform all duties related to the study. All services were provided as part of routine care at Burrell and used regular payor sources for patient services.

\section{PS-108}

Once-daily Dosing of Iloperidone in Patients With Schizophrenia Switched From Twice-daily Dosing Adam Winseck, PhD; Saeeduddin Ahmed, MD; Xiangyi Meng, PhD; Marla Hochfeld, MD

Study Objectives: The present study investigated the relationship between TSH and Metabolic Syndrome (MetS) in psychiatric patients treated with an antipsychotic medication.

Method: A total of 117 patients undergoing psychiatric treatment at a community mental health center in Southwest Missouri were included in the study. Retrospective data collection was used to identify patients over the age of 18 who were also receiving treatment with an antipsychotic medication and had both a metabolic and a TSH screening in the 12 months prior to the chart abstraction. Primarily physiological measures were collected including height, weight, body mass index, waist circumference, and blood pressure as well as fasting glucose, triglyceride, cholesterol, and TSH levels. The presence of MetS was identified and compared to TSH levels and other physiological measures. Correlations, discriminant analyses, and a relative operating characteristics (ROC) curve were used to examine the relationship between these TSH levels and MetS.

Results: A statistically significant relationship between TSH levels and presence of MetS, $\chi 2(1)=23.04, p<.001$, was identified; patients who had MetS were significantly more likely to have a TSH level that was out of range. TSH levels correlated with several subcomponents of MetS, including waist circumference $(\mathrm{r}=.320, \mathrm{p}<.001)$, diastolic blood pressure $(r=.243, p=.008)$, HDL $(r=-.265, p=.004)$, and triglycerides $(r=.477, p<.001)$. 
According to the discriminant analysis, a significant mean difference was observed in TSH levels between cases where MetS was present $(\mathrm{M}=4.35, \mathrm{SD}=2.39)$ and not present $(\mathrm{M}=2.15, \mathrm{SD}=1.79), \mathrm{F}=30.31, \mathrm{p}<.001$. The ROC analysis indicated that using an overall TSH cutoff of 2.54 to predict the presence of MetS yielded the best balance between sensitivity $(76.9 \%)$ and specificity $(75 \%)$.

Conclusions: These results indicate that the relationship between TSH level and MetS is strong enough to allow for TSH to serve as means of screening for the likelihood of MetS in certain clinical populations who may have an increased risk of MetS. Though TSH and MetS are shown here to be associated with one another in this population, the underlying root of this association remains unclear.

Burrell Behavioral Health provided the necessary resources to perform all duties related to the study. All services were provided as part of routine care at Burrell and used regular payor sources for patient services.

\section{PS-109}

Efficacy and Safety of EB-1010, a Triple Reuptake Inhibitor, in the Treatment of Patients with Major Depressive Disorder

Pierre V. Tran, MD, MMM; Phil Skelnick, PhD; Nuo-Yu Huang, MD, PhD; Mark Bradshaw, PhD

Study Objectives: EB-1010 (formerly known as DOV21, 947) is a novel, unbalanced triple reuptake monoamine uptake inhibitor with a relative potency to inhibit serotonin, norepinephrine and dopamine uptake of $\sim 1: 2: 8$, respectively. The present study tested the hypothesis that the broad spectrum mechanistic profile of EB-1010 also translates into unique antidepressant activities in humans, with perhaps enhanced efficacy such as improvement of anhedonia (a core symptom of depression), presumably linked to a deficit in mesocorticolimbic dopaminergic function, as well as a reduced liability to induce sexual dysfunction, weight gain and cognitive dysfunction, adverse events typically associated with selective serotonin reuptake inhibition.

Method: The study was a 6-week, multi-center, randomized, double-blind, parallel, placebo-controlled study of 63 patients with Major Depressive Disorder (MDD). Eligible patients (HAMD-17 $\geqslant 22$ at Baseline) were randomized to receive either EB-1010 $25 \mathrm{mg}$ BID for 2 weeks and then $50 \mathrm{mg}$ BID for 4 weeks or placebo. Key outcome measures included the MADRS (primary), the HAMD-17 (administered via IVRS), the CGI-I, the CGI-S, and the Derogatis Interview for Sexual Functioning Self-Report (DISF-SR).

Results: The modified intent-to-treat population (MITT, $\mathrm{n}=56)$ showed the following combined (placebo and EB-1010) mean baseline scores on the main outcome measures: MADRS (31.4) (primary); HAMD-17 (29.6) (secondary); and DISF-SR (25.4). At the end of the double-blind treatment (Week 6), the estimated LS mean change from baseline (MMRM or mixed model repeated measures) in the MADRS total scores was statistically significantly superior for EB-1010 when compared to placebo (18.16 vs. 21.99; $p=0.028)$, with an overall statistical effect size of -0.63 (Cohen's d). When assessed with the CGI-I, a global impression scale sensitive to clinically relevant changes in improvement status, treatment with EB-1010 was also statistically significantly superior to placebo ( $p=0.03$; Week 6; MMRM). An anhedonia factor score grouping Items 1 (apparent sadness), 2 (reported sadness), 6 (concentration difficulties, 7 (lassitude) and 8 (inability to feel) of the MADRS demonstrated a statistically significant difference in favor of EB-1010 in comparison to placebo $(p=0.049)$. EB-1010 was relatively well tolerated. Two patients in each treatment group discontinued the study early due to AEs but no serious AEs were reported. No statistically significant difference was observed between EB-1010 and placebo when assessed with the DISF-SR.

The research reported here was supported by Euthymics Bioscience.

\section{PS-110}

Minimal Change in Metabolic Parameters Following Long-term Iloperidone Use

Marla Hochfeld, MD; Saeeduddin Ahmed, PhD; Xiangyi Meng, PhD; Adam Winseck, PhD

Study Objective: Antipsychotic medication may contribute to schizophrenia patients' increased risk of cardiovascular disease. Metabolic data from patients with schizophrenia and schizoaffective disorder were pooled from 9 phase II and III placebo- and active-controlled iloperidone studies with double-blind phases of 4-6 weeks, and double-blind and/or open-label extensions of up to 2 years.

Methods: Weight and blood samples were taken from fasted subjects in 1 study and from a mix of fasted and nonfasted subjects in the other 8. Mean changes in these parameters from baseline to various timepoints were calculated. 
Results: Respective mean weight changes from baseline (in $\mathrm{kg}$ ) with iloperidone $10-16 \mathrm{mg} / \mathrm{d}$ and $20-24 \mathrm{mg} / \mathrm{d}$ were: $3.0(n=850) / 2.8(n=33)$ for 3-6 months; $3.4(n=725) / 1.8(n=31)$ for $6-12$ months; and $3.0(n=425) / 1.5$ $(n=20)$ beyond 12 months. Weight gain was not associated with clinically meaningful glucose or lipid changes. Respective mean glucose changes (in $\mathrm{mg} / \mathrm{dL})$ for these 2 dose groups were: $1.8(\mathrm{n}=773) /-3.6(\mathrm{n}=34)$ at $3-6$ months; $5.4(\mathrm{n}=723) /-9.0(\mathrm{n}=31)$ at 6-12 months; and $5.4(\mathrm{n}=425) /-18.0(\mathrm{n}=20)$ beyond 12 months. Respective mean triglyceride changes (in mg/dL) were: $-8.9(n=783) /-26.6(n=34)$ at 3-6 months; $-8.9(n=726) /-35.4$ $(\mathrm{n}=31)$ at 6-12 months; and $-17.7(\mathrm{n}=428) /-17.7(\mathrm{n}=20)$ beyond 12 months. Respective mean total cholesterol changes (in mg/dL) were: $-3.9(\mathrm{n}=783) /-19.4(\mathrm{n}=34)$ at 3-6 months; $-3.9(\mathrm{n}=726) /-23.2(\mathrm{n}=31)$ at $6-12$ months; and $-7.7(n=428) /-19.4(n=20)$ beyond 12 months.

Conclusion: Iloperidone $10-24 \mathrm{mg} / \mathrm{d}$ demonstrated minimal changes in lipids or glucose in up to 2 years of treatment, with modest initial weight gain that stabilized over time.

Funding for this study was provided by Novartis Pharmaceuticals Corporation.

\section{PS-111}

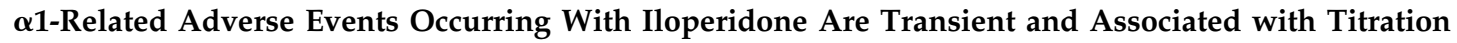

Peter J. Weiden, MD; Saeeduddin Ahmed, PhD; Xiangyi Meng, PhD; Adam Winseck, PhD

Study Objectives: The $\boldsymbol{\alpha} 1$ adrenoceptor plays a key role in sympathetic control of autonomic responses. For example, the $\boldsymbol{\alpha} 1$ receptor is found on smooth muscles in the arteriole endothelium, and norepinephrine binding to $\boldsymbol{\alpha} 1$ maintains adequate blood pressure following sudden shifts in body position (eg, standing up suddenly). Iloperidone, an atypical antipsychotic indicated for treatment of schizophrenia, has strong $\boldsymbol{\alpha} 1$-receptor affinity that is often associated with orthostatic hypotension, dizziness, and tachycardia. To address the clinical impact of $\boldsymbol{\alpha} 1$ antagonism, the severity and time course of orthostatic hypotension, tachycardia and dizziness as adverse events (AEs) were followed after fixed titrations to various iloperidone doses.

Methods: Data from 9 clinical trials of iloperidone treatment that enrolled patients with schizophrenia or schizoaffective disorder were pooled in this analysis. In each study, patients were titrated to reach an iloperidone dose of $4-8 \mathrm{mg} / \mathrm{d}(\mathrm{n}=1225), 10-16 \mathrm{mg} / \mathrm{d}(\mathrm{n}=1533), 20-24 \mathrm{mg} / \mathrm{d}(\mathrm{n}=452)$ or placebo $(\mathrm{n}=587)$ during a fixed period of between 6 and 11 days. Titration therefore occurred more rapidly with higher doses than with lower ones.

Results: At Week 1, following titration to $20-24 \mathrm{mg} / \mathrm{d}$, AE reports were $2.9 \%$ for orthostatic hypotension, $12.6 \%$ for dizziness, and $6.4 \%$ for tachycardia. Slower titration to the lower target doses of $4-8 \mathrm{mg} / \mathrm{d}$ and $10-16 \mathrm{mg} / \mathrm{d}$ produced respective $\mathrm{AE}$ rates of $1.1 \%$ and $0.9 \%$ for orthostatic hypotension, $5.4 \%$ and $5.2 \%$ for dizziness, and $2.0 \%$ and $1.0 \%$ for tachycardia. During weeks $2-6$, incidence rates for the combined iloperidone dose groups decreased to $0.3 \%-0.6 \%$ for orthostatic hypotension, $0.9 \%-2.2 \%$ for dizziness, and $0.2 \%-0.5 \%$ for tachycardia. Greater than $90 \%$ of these iloperidone AEs were mild to moderate in severity.

Conclusion: Based on $\boldsymbol{\alpha} 1$-receptor AE reports during the initial week of treatment, slower titration to between 4 and $16 \mathrm{mg} / \mathrm{d}$ of iloperidone conferred a lower rate of orthostatic hypotension, dizziness and tachycardia than did more rapid titration to $20-24 \mathrm{mg} / \mathrm{d}$. Overall, $\boldsymbol{\alpha} 1$-receptor-related AEs were mild to moderate and were transient, as rates decreased sharply after Week 1.

Funding for this study was provided by Novartis Pharmaceuticals Corporation.

\section{PS-112}

Personalized Therapy of Adjunctive L-methylfolate to Selective Serotonin Reuptake Inhibitor-Resistant Major Depressive Disorder

George I. Papakostas, MD; Richard C. Shelton, MD; John M. Zajecka, MD; Maurizio Fava, MD

Study Objectives: Evaluate the efficacy and safety of adjunctive L-methylfolate $15 \mathrm{mg}$ as well as the effect of specific biomarkers in a multi-center, double-blind, placebo-controlled trial of L-methylfolate used as an adjunct to selective serotonin reuptake inhibitors (SSRIs) in a sequential parallel comparison study design.

Methods: 75 outpatients with SSRI-resistant MDD were enrolled in a 60-day study, which was divided into two, 30-day periods (phases I and II). Patients were randomized, in a 2:3:3 fashion, to receive either L-methylfolate $15 \mathrm{mg} /$ day for 60 days, placebo for 30 days followed by L-methylfolate $15 \mathrm{mg} /$ day for 30 days, or placebo 
for 60 days. SSRI doses were kept constant during the double-blind phase of the study. Secondary genomic and biomarker endpoints were evaluated to determine if there was a difference in treatment effect.

Results: The results of the trial indicated greater efficacy for adjunctive L-methylfolate $15 \mathrm{mg} /$ day versus continued SSRI therapy plus placebo (degree of change and response rates according to the Hamilton Depression Rating Scale (HDRS-17); $\mathrm{p}=0.05$ and $\mathrm{p}=0.04$, respectively). Treatment effect were similar in patients with baseline 5-MTHF (L-methylfolate) below median compared to those with 5-MTHF above median (phase-pooled HDRS-17 reductions -0.42 vs. -0.51 , respectively). There was a numerically greater treatment effect in patients with an allelic variant in the MTHFR (methylentetrahydrofolate reductase) C677 $\mathrm{T}$ genotype (phase-pooled reduction in HDRS-17 of -3.44 for ' $t$ ' allele vs.-1.41 for ' $c c^{\prime}$ ' allele). Additionally patients with a BMI $>30$ experienced a significantly greater reduction in depressive symptoms (phase-pooled reduction in HDRS-17 of $-4.60 ; \mathrm{p}=0.001$ ) whereas those with a BMI $<30$ did not (phase-pooled increase of $+1.83, p=0.298$ ).

Conclusion: $15 \mathrm{mg} /$ day of adjunctive L-methylfolate may represent an effective, safe, and relatively well tolerated adjunct treatment strategy for MDD patients who are SSRI partial- and non-responders, particularly in patients with a BMI $>30$ and possibly in patients with the MTHFR C677 T ' $t$ ' allele.

Study was supported by a grant from Pamlab, LLC

PS-113

L-methylfolate $15 \mathrm{mg}$ as Adjunctive Therapy with SSRI Following Acute Remission for MDD: Results of a 12-Month, Open-Label, Relapse-Prevention Study

John M. Zajecka, MD; Richard C. Shelton, MD; Maurizio Fava, MD; George I. Papakostas, MD

\begin{abstract}
L-methylfolate has been shown to be an effective, safe, and well-tolerated adjunct treatment for patients with partial or no response to an SSRI for the acute treatment of MDD (1). Twelve-month, open-label data will provide clinical information on the long-term efficacy, safety, and tolerability of adjunctive L-methylfolate $15 \mathrm{mg}$ to SSRI partial/non-responders following remission in a double-blind, placebo-controlled acute study.
\end{abstract}

Method: Thirteen subjects who achieved remission entered the continuation/maintenance phase of open-label treatment with SSRI+L-methylfolate $15 \mathrm{mg}$.Subjects were maintained on $15 \mathrm{mg}$ of L-methylfolate + SSRI and scheduled follow-up visits every 12 weeks for safety and tolerability, and assessed for relapse/recurrence ( HDRS-17 $>15$ ), and sustaining remission status ( HDRS-17 $\leqslant 7$ ) at endpoint.

Results: Eleven $(85 \%)$ of the 13 remitted subjects from acute treatment phase competed the 12-month open-label phase. One patient was lost to follow-up (visit 7, HDRS-10) and one patient discontinued due to non-compliance (visit 9, HDRS-10). No subject experienced relapse/recurrence criteria (HDRS-17 $>15$ ) at any time point, and at the end of 12 months of treatment, and $53.8 \%$ of the subjects sustained full remission (HRDS- $17 \leqslant 7$ ) at the end of 12 months of treatment.

There were no serious adverse events, no discontinuations due to adverse events, and no clinically significant new onset adverse events reported during the 12 month, open-label phase for the remitted subjects $(n-13)$ on L-methylfolate $15 \mathrm{mg}$ adjunctive to SSRI.

Conclusions: This study suggests that the use of L-methylfolate $15 \mathrm{mg}$ as an adjunct to SSRI partial and nonresponders is a safe, well-tolerated and effective treatment at preventing relapse/recurrence of MDD in the majority of patients treated for 12 months following acute remission. Study limitations include the open-label of the long-term treatment; however, all subjects enrolled in the long-term study achieved remission following a double-blind, placebo controlled acute trial. The high subject retention rates, lack of relapse/recurrence, and high rate of sustained remission suggests that future research is needed in order to clarify the role of L-methylfolate to enhance the likelihood of achieving and sustaining remission in MDD.

Study was supported by a grant from Pamlab, LLC

PS-114

Primary and Behavioral Health Integration: The Building Exceptional Wellness (BE Well) Project Bethany A. Murray, RN, PMHCNS-BC

Abstract: Persons with serious mental illnesses die up to 25 years earlier than the general population from cardiovascular or respiratory disease, infections and diabetes. Tobacco use, diet, and physical inactivity are causative factors of most serious health disorders. The goal of the BE Well project is to reduce the risk of early death in adults with SMI by improving overall wellness and by reducing causative 
factors. To meet this goal, the following questions were posed: What type of program will be most effective in reducing risk factors and improving the health of persons with SMI? Which components will have the most impact? What are the barriers and challenges of implementing medial programs within a behavioral health care setting? What are the unique needs of the SMI population?

BE Well is located in a CMHC in Indiana. Participation is voluntary. Clients were selected based the presence of an SMI diagnosis and at least 1 of 5 risk factors. 37 clients completed pre/post-test assessments ( $83 \%$ white, 7\% black, 78\% female). Data included $\mathrm{B} / \mathrm{P}$, weight, BMI, fat \%, FBS, HgbA1C, and lipids. Paired-samples t-tests were used to compare pre and post weights and gender. Linear regression was used to determine if \# of days in the program or BMI were predictive of greater weight loss. Process data was obtained from the program staff. The program consisted of physical care management by an NP/MD, nursing assessments, educational groups, supervised exercise outings and meetings with a care coordinator.

Total weight loss of $348 \mathrm{lbs}$ occurred in $75 \%$ of clients. Individual weight loss mean was significant at $8.97 \mathrm{lbs}(\mathrm{SD}=12.299)$; $\mathrm{t}(34)=4.32, \mathrm{p}<.001$. Female clients lost an average of $8.46 \mathrm{lbs} ; \mathrm{t}(23)=3.53, \mathrm{p}=.002$. Male clients lost an average of $10.091 \mathrm{lbs}$; $\mathrm{t}(10)=2.40, \mathrm{p}=.037$. Each day of participation was associated with a .069 lbs weight decrease $(\mathrm{t}=-1.82, \mathrm{p}=.077)$. Each unit increase in BMI score at baseline was associated with a $0.380 \mathrm{lbs}$ decrease at follow-up; $\mathrm{t}=-2.30, \mathrm{p}=.028$.

Five themes were identified as important in integrating physical care in a mental health setting: 1) personnel decisions; 2) program structure; 3) healthcare culture; 4) agency integration; and 5) client issues.

The BE Well program works. Clients lost weight and were actively engaged in their care. Limitations include a lack of lab test follow-through and sample size. Future work will compare type and quantity of program participation to determine which specific components of BE Well were most helpful.

\section{PS-115}

Meta-analyses of the Efficacy of Asenapine Versus Placebo in Bipolar I Disorder Compared With Other Atypical Antipsychotics

Hein Fennemaa; Bernhard Slaapa; Armin Szegedib

Study Objective: Meta-analyses were performed to compare the efficacy of the atypical antipsychotic (AAP) asenapine with other AAPs based on placebo-controlled trials in patients experiencing acute manic or mixed episodes associated with bipolar disorder.

Methods: The primary endpoint for the majority of the included studies was change from baseline in the Young Mania Rating Scale (YMRS) total score versus placebo at week 3 . For asenapine ( 5 or $10 \mathrm{mg}$ twice daily), data were obtained from two 3-week monotherapy trials and one 12-week adjunctive treatment trial in patients showing an incomplete response to lithium or valproate monotherapy. Data for other AAPs were obtained from 17 monotherapy trials and 9 adjunctive treatment trials. Meta-analyses used a random effects model.(1) Monotherapy and adjunctive therapy were analyzed separately.

Results: Treatment effects varied substantially across agents and trials. For monotherapy, the YMRS total score change from baseline with asenapine exceeded placebo by 4.5 points (95\% CI: $2.5-6.4 ; \mathrm{P}<0.0001)$. This was comparable to the treatment effect of all AAPs versus placebo (4.8 points; 95\% CI: 3.7-6.0; P<0.0001). The treatment effect for adjunctive asenapine exceeded placebo by 2.4 points (95\% CI: $0.5-4.3$; $\mathrm{P}=0.0257)$. This was also comparable to the overall treatment effect for combined AAPs (2.6 points; 95\% CI: 1.9-3.3; P $<0.0001)$.

Conclusions: These meta-analyses demonstrate the statistical superiority of asenapine over placebo, as monotherapy or as adjunctive therapy to lithium or valproate, for acute mania in patients with bipolar disorder. Efficacy of asenapine is similar to other AAPs used as monotherapy or adjunctive therapy.

This research was supported by Merck.

\section{PS-116}

Incidence, Onset, and Duration of Treatment-Emergent Somnolence With Asenapine in Patients With Schizophrenia or Bipolar Disorder

Pilar Cazorla, PhD; Jun Zhao; Armin Szegedi, MD

Study Objective: Meta-analyses were performed to compare the efficacy of the atypical antipsychotic (AAP) asenapine with other AAPs based on placebo-controlled trials in patients experiencing acute manic or mixed episodes associated with bipolar disorder. 
Methods: The primary endpoint for the majority of the included studies was change from baseline in the Young Mania Rating Scale (YMRS) total score versus placebo at week 3. For asenapine (5 or $10 \mathrm{mg}$ twice daily), data were obtained from two 3-week monotherapy trials and one 12-week adjunctive treatment trial in patients showing an incomplete response to lithium or valproate monotherapy. Data for other AAPs were obtained from 17 monotherapy trials and 9 adjunctive treatment trials. Meta-analyses used a random effects model.(1) Monotherapy and adjunctive therapy were analyzed separately.

Results: Treatment effects varied substantially across agents and trials. For monotherapy, the YMRS total score change from baseline with asenapine exceeded placebo by 4.5 points (95\% CI: 2.5-6.4; $\mathrm{P}<0.0001)$. This was comparable to the treatment effect of all AAPs versus placebo (4.8 points; 95\% CI: 3.7-6.0; P < 0.0001). The treatment effect for adjunctive asenapine exceeded placebo by 2.4 points $(95 \% \mathrm{CI}: 0.5-4.3 ; \mathrm{P}=0.0257)$. This was also comparable to the overall treatment effect for combined AAPs (2.6 points; 95\% CI: 1.9-3.3; P $<0.0001$ ).

Conclusions: These meta-analyses demonstrate the statistical superiority of asenapine over placebo, as monotherapy or as adjunctive therapy to lithium or valproate, for acute mania in patients with bipolar disorder. Efficacy of asenapine is similar to other AAPs used as monotherapy or adjunctive therapy.

This research was supported by Merck.

\section{PS-117}

Long-Term Safety and Tolerability of Lurasidone in Patients With Schizophrenia: Results of a 6-Month, Open-Label Extension Study

Barry Herman, MD, MMM; Stephen M. Stahl, MD, PhD; Josephine Cucchiaro, PhD;

Doreen Simonelli, PhD

Study Objectives: The aim of this study was to evaluate the safety and tolerability of lurasidone in the long-term treatment of schizophrenia, and to determine if improvement during acute double-blind (DB) treatment was sustained.

Methods: Patients who completed a 6-week, DB, placebo- and active-controlled trial evaluating the efficacy of lurasidone $40 \mathrm{mg}$ and $120 \mathrm{mg}$, and olanzapine $15 \mathrm{mg}$ (active control to confirm assay sensitivity) in acute exacerbation of schizophrenia were eligible to participate in a 6-month open-label extension (OLE) study in which patients received flexibly-dosed lurasidone $40-120 \mathrm{mg} /$ day. Safety and tolerability measures included adverse events (AEs), body weight, lipid profile, HbA1c, insulin, prolactin, and ECGs. Efficacy assessments included the Positive and Negative Symptoms of Schizophrenia Scale (PANSS) total score.

Results: The mean PANSS total score for all patients $(\mathrm{N}=246)$ who continued into the OLE decreased from 96.6 (at the baseline of the initial 6-week DB study) to 66.6 at the baseline of the 6-month OLE. Continued treatment during the OLE resulted in further improvement in the PANSS total score, with a mean (SD) change of -3.0 (16.3) on an LOCF endpoint analysis, and -8.7 (14.4) on an observed case analysis. During OLE treatment, two AEs occurred with an incidence $>10 \%$ : akathisia $(13.0 \%)$ and insomnia $(11.0 \%) ; 7.3 \%$ of patients reported experiencing a severe $\mathrm{AE}$, while $12.2 \%$ of patients discontinued due to an $\mathrm{AE}$. There were no clinically meaningful changes in vital signs, or laboratory and ECG parameters; one subject experienced $>60 \mathrm{msec}$ increase in QTcF, and no subject had a QTcF interval $>500$ msec. Patients who continued receiving lurasidone had no clinically meaningful changes from open-label baseline to endpoint in cholesterol $(-7.1 \mathrm{mg} / \mathrm{dL})$, LDL $(-2.6 \mathrm{mg} / \mathrm{dL})$, triglycerides $(-18.3 \mathrm{mg} / \mathrm{dL})$, insulin $(-2.4 \mathrm{mU} / \mathrm{L})$, or whole blood HbA1c $(-0.06 \%)$. Prolactin, which had increased during the DB study $(+3.2$ $\mathrm{ng} / \mathrm{mL}$ on combined lurasidone; $+3.4 \mathrm{ng} / \mathrm{mL}$ on olanzapine), showed an overall median decrease $(-1.3 \mathrm{ng} / \mathrm{mL})$ during the OLE. Body weight and BMI remained relatively stable during the open-label extension, except for patients who had been randomized in the preceding acute DB study to olanzapine $15 \mathrm{mg}$. These patients experienced a mean (SD) reduction of $-1.8(4.9) \mathrm{kg}$ in weight after being switched to lurasidone in the OLE

Conclusions: During this 6-month, open-label extension study, flexibly dosed lurasidone (40-120 mg, daily) was welltolerated in patients with schizophrenia. Lurasidone showed low potential for weight gain and dyslipidemia in patients treated for up 8 months (acute and extension study treatment, combined). PANSS total score reductions observed after 6-week acute DB treatment with lurasidone were sustained in this 6-month open-label extension study.

\section{PS-118}

Weight Change and Metabolic Effects of Asenapine in Placebo- or Olanzapine-Controlled Studies R Landbloom, a J Zhao, a P Cazorla, a J Schoemaker, a M Mackle, a L Snow-Adami, a J Panagides, c A Szegedia 
Study Objective: We conducted post-hoc analyses of the weight change and metabolic effects associated with asenapine in adults.

Methods: Data were pooled from phase 2 and phase 3 trials in schizophrenia and bipolar disorder of asenapine versus placebo $(n=1748$; duration, $1-6 \mathrm{wk})$ and/or olanzapine $(n=3430$; duration, 3->100 wk). Asenapine dosages were 5 or $10 \mathrm{mg}$ twice daily (2-20 mg twice daily in 2 studies); olanzapine dosages were 5 to $20 \mathrm{mg}$ once daily. Inferential analyses using analysis of variance assessed change at endpoint from baseline weight, body mass index, and fasting lipids and glucose.

Results: Weight change with asenapine was significantly less than olanzapine $(0.9 \pm 0.1$ vs $3.1 \pm 0.2 \mathrm{~kg}$; $\mathrm{P}<0.0001)$ and significantly exceeded placebo (least squares mean $\pm \mathrm{SD}: 1.2 \pm 0.2 \mathrm{~kg}$ vs $0.1 \pm 0.2 \mathrm{~kg} ; \mathrm{P}<0.0001$ ). Changes in total cholesterol, low-density lipoprotein (LDL), and high-density lipoprotein (HDL) cholesterol did not significantly differ for asenapine versus placebo, but triglyceride changes did significantly differ (asenapine, $1.8 \pm 6.3 \mathrm{mg} / \mathrm{dL}$; placebo, $-12.2 \pm 5.9 \mathrm{mg} / \mathrm{dL} ; \mathrm{P}<0.05$ ). Changes (asenapine vs olanzapine) significantly differed for total cholesterol $(-0.4 \pm 1.1$ vs $6.2 \pm 1.2 \mathrm{mg} / \mathrm{dL}$, respectively; $\mathrm{P}<0.0001)$, LDL $(-0.3 \pm 1.1$ vs $3.1 \pm 1.2 \mathrm{mg} / \mathrm{dL}, \mathrm{P}<0.05)$, fasting triglycerides $(-0.9 \pm 5.4$ vs $24.3 \pm 5.8 \mathrm{mg} / \mathrm{dL}, \mathrm{P}<0.0001)$, and $\mathrm{HDL}(1.3 \pm 0.4$ vs $-0.2 \pm 0.4 \mathrm{mg} / \mathrm{dL}, \mathrm{P}<0.01)$. Changes in fasting glucose with asenapine significantly exceeded placebo $(1.9 \pm 1.7$ vs $-1.6 \pm 1.5 \mathrm{mg} / \mathrm{dL} ; \mathrm{P}<0.05)$ and were numerically lower than olanzapine $(2.0 \pm 1.3 \mathrm{vs} 3.3 \pm 1.3 \mathrm{mg} / \mathrm{dL})$.

Conclusion: These post-hoc pooled analyses suggest that, on average, asenapine was associated with greater increases in weight and glucose levels compared with placebo. Relative to baseline levels, triglycerides decreased with placebo and did not substantially change with asenapine. Compared with olanzapine, asenapine had a lower propensity to induce weight gain or to increase serum lipids, including triglycerides, LDL, and cholesterol.

This research was supported by Merck.

\section{PS-119}

Meta-analysis of the Efficacy of Asenapine for Acute Schizophrenia: Comparisons With Placebo and other Atypical Antipsychotics

Armin Szegedi, a Pierre Verweij, b Wilbert van Duijnhoven, b Mary Mackle, a Pilar Cazorla, a Hein Fennemab

Study Objective: To characterize the relative efficacy of asenapine for acute schizophrenia using all randomized head-to-head comparisons to active controls from asenapine clinical trials and published randomized head-to-head comparisons of other atypical antipsychotics (AAPs).

Methods: Change from baseline Positive and Negative Syndrome Scale (PANSS) total score were assessed using last observation carried forward (LOCF) and mixed model for repeated measures (MMRM). Comparisons of asenapine and other antipsychotics from the same asenapine trials versus placebo were based on 4 placebo-controlled asenapine studies; meta-analyses involving asenapine trials used individual patient data. Head-to-head comparisons among all AAPs (including those for which no direct comparisons are available) were conducted with network meta-analyses using a published database of 49 studies1 that was updated with data from 4 AAP-controlled asenapine trials.

Results: Change from baseline in PANSS total score with asenapine exceeded that with placebo (LOCF: 3.6 [95\% CI, 1.3-5.8; $\mathrm{P}=0.002)$; MMRM: 4.1 [95\% CI, 1.6-6.6; P = 0.001]); this treatment effect was comparable to active controls used in the same trials (LOCF: 4.0 [95\% CI, 1.5-6.5; P = 0.002); MMRM: 4.8 [95\% CI, 2.0-7.6; P = 0.001]). Head-to-head network meta-analyses reported comparable efficacy with asenapine and other AAPs; PANSS differences ranged from 3.9 points greater than ziprasidone $(95 \% \mathrm{CI}, 0.3-7.4)$ to 2.9 points less than olanzapine (95\% CI, $-5.9-0.1)$.

Conclusion: These meta-analyses demonstrate the superiority of asenapine over placebo in acute schizophrenia, with the treatment effects of asenapine being comparable to antipsychotics used in the same trials. The network meta-analysis suggests the efficacy of asenapine for acute schizophrenia is comparable to established AAPs.

This research was supported by Merck.

\section{PS-120}

Comparative Receptor Binding Profile of Lurasidone and Other First and Second Generation Antipsychotics Takeo Ishiyama, PhD; Antony Loebel, MD; Josephine Cucchiaro, PhD; T. Horisawa, BS; K. Tokuda, BS; Masaaki Ogasa, MS; T. Ishibashi, PhD; Peter Werner, Ph.D; Stephen M. Stahl, MD, PhD 
Study Objective: To characterize the receptor binding profile of lurasidone compared to previously introduced first and second generation antipsychotics.

Methods: Binding affinities for lurasidone and other antipsychotics were determined in side-by-side assays using membrane preparations from non-human CNS or cell lines expressing cloned human receptors.

Results: Lurasidone displayed potent binding and full antagonism at dopamine $\mathrm{D}_{2}(\mathrm{Ki}, 1.68 \mathrm{nM})$ and $5-\mathrm{HT}_{7}$ $(\mathrm{Ki}, 0.49 \mathrm{nM})$ receptors; lurasidone's had the highest affinity for the dopamine $\mathrm{D}_{2}$ receptor among the antipsychotics tested in our study, followed by risperidone and haloperidol. Lurasidone also showed full antagonism and high affinity at serotonin 5- $\mathrm{HT}_{2 \mathrm{~A}}$ receptors $(\mathrm{Ki}, 2.03 \mathrm{nM})$. Lurasidone had nanomolar affinity $(\mathrm{Ki}=6.75 \mathrm{nM})$ for serotonin $5-\mathrm{HT}_{1 \mathrm{~A}}$ receptors, behaving as a weak-moderate partial agonist. Relative to respective dopamine $\mathrm{D}_{2}$ receptor binding, lurasidone showed higher affinity for 5- $\mathrm{HT}_{7}, 5-\mathrm{HT}_{2 \mathrm{~A}}$, and 5- $\mathrm{HT}_{1 \mathrm{~A}}$ than the other antipsychotic agents tested here. Lurasidone's binding to dopamine receptors was selective for dopamine $\mathrm{D}_{2}$ receptors: Compared to its dopamine $D_{2}$ receptor affinity, its $\mathrm{Ki}$ for $\mathrm{D}_{1}$ receptors was 156-fold higher, for $\mathrm{D}_{3} 16$-fold higher, and 30-fold higher for $\mathrm{D}_{4}$ receptors. Lurasidone had a favorable binding-profile at several receptors that are suspected of being associated with undesirable effects, demonstrating minimal affinity for $5-\mathrm{HT}_{2 \mathrm{C}}$ receptors $(\mathrm{Ki}, 415 \mathrm{nM})$, and no affinity for histamine $\mathrm{H}_{1}\left(\mathrm{IC}_{50}>1000 \mathrm{nM}\right)$ and muscarinic [cholinergic] $\mathrm{M}_{1}$ $\left(\mathrm{IC}_{50}>1000 \mathrm{nM}\right)$ receptors. In contrast, clozapine and olanzapine both showed potent binding to $\mathrm{H}_{1}(\mathrm{Ki}, 2.0 \mathrm{nM}$ and $3.8 \mathrm{nM}$, respectively) and $\mathrm{M}_{1}$ receptors $(\mathrm{Ki}, 4.9 \mathrm{nM}$ and $7.6 \mathrm{nM}$, respectively). Lurasidone also displayed only moderate affinity for $\boldsymbol{\alpha}_{2 \mathrm{C}}$ adrenoceptors $(\mathrm{Ki}, 10.8 \mathrm{nM})$, and moderate-weak affinity for $\boldsymbol{\alpha}_{1}$ adrenoceptors $(\mathrm{Ki}, 48 \mathrm{nM})$.

Conclusions: The receptor binding profile of lurasidone is characterized by its potent and selective antagonist activity at dopamine $\mathrm{D}_{2}$ receptors, potent binding and antagonism at both $5-\mathrm{HT}_{7}$ and $5-\mathrm{HT}_{2} \mathrm{~A}$ receptors, and nanomolar affinity and partial agonism to $5-\mathrm{HT}_{1 \mathrm{~A}}$ receptors. Lurasidone showed minimal-absent affinity for the serotonergic $5-\mathrm{HT}_{2} \mathrm{C}$, histamine $\mathrm{H}_{1}$, and the muscarinic [cholinergic] $\mathrm{M}_{1}$ receptors. This profile is consistent with the expected antipsychotic efficacy, a moderate likelihood of EPS, a low potential for weight gain and related metabolic consequences, and the potential for beneficial impact on mood and impaired cognitive function.

This study was funded by Sunovion Pharmaceuticals, Inc.

\section{PS-121}

Clinical Practice Informing Drug Development Targets in ASD

Jessica A. Hellings, MB. BCh., M. Med. Psych (SA); Andrew Thome, MS; Irfan Bhatti, MD; Galen Cook-Wiens, MS

Study Objectives: Autism drug development is minimal (CDC) in spite of a growing and urgent need. Available drugs are often required in combination. Amitriptyline (AMI) is a TCA with NE and 5HT reuptake inhibition we have used cautiously for 20 yrs, at times with stimulants, and also risperidone (RIS) to treat youth with ASD and moderate to severe ADHD symptoms of hyperactivity and impulsivity. AMI may produce less activation than atomoxetine and benefits impulsive aggression, sleep, appetite and enuresis. We will critically discuss a chart review of 50 youth outcomes, of mostly previously treatment-resistant patients.

Method: Data was analyzed from clinic charts: Age at AMI start, gender, diagnoses, prior ADHD drugs, AMI duration, final dose, trough level, concomitant medications, starting and final BP, pulse, height, weight, QTc and AEs. Outcomes were \% CGI-I? 2 at follow-up visits on AMI, and total number of visits.

Results: Mean age 9.4 yrs; 10 females, 40 males. All met DSM-IV-TR criteria for ASD and ADHD. 90\% presented with aggression, $50 \%$ with self-injury, 30\% had failed atomoxetine, and $40 \%$ had failed 3 or more ADHD drug trials. Mean dose was $1.27 \mathrm{mg} / \mathrm{kg} /$ day; mean level $114.6 \mathrm{ng} / \mathrm{mL}$; mean duration $3.4 \mathrm{yrs} .32 \%$ received stimulants, $48 \%$ received RIS. $82 \%$ had CGI-I? 2 for at least $50 \%$ of follow-ups; $52 \%$ had CGI-I ? 2 at $66 \%$ or more visits. Mean total visits was 15.6 . QTc increased in $63 \%$ of individuals mostly within the normal range, cardiology consults were obtained in 8\%. AMI dose was lowered due to AEs in 14 subjects and discontinued in 3.

Conclusions: AMI was very effective and tolerated in combination treatments in most cases of treatment-resistant ASD and ADHD. AMI should not be used in combination with lithium or other medications predisposing to QTc prolongation. Discussion will focus on AMI mechanisms of action and drug development avoiding QTC prolongation. 


\section{PS-122}

Long-Term Safety And Tolerability Of Lurasidone In Schizophrenia or Schizoaffective Disorder: A 12-Month, Double-Blind, Active-Controlled Study

Lyle K. Laird, PharmD, BCPP; Leslie Citrome, MD, MPH; Josephine Cucchiaro, PhD;

Kaushik Sarma, MD; Debra Phillips, Robert Silva, PhD; Satoru Tsuchiya, MS; Antony Loebel, MD

Study Objectives: To evaluate the long-term safety of lurasidone in the treatment of schizophrenia or schizoaffective disorder.

Methods: Adult outpatients who met DSM-IV criteria for chronic, stable schizophrenia were randomized to 12 months of double-blind once-daily treatment with flexibly-dosed, lurasidone 40,80 or $120 \mathrm{mg}$, or risperidone 2,4 or $6 \mathrm{mg}$.Safety and tolerability measures included adverse events (AEs), body weight, lipid parameters, prolactin, and ECGs. Efficacy assessments included the Positive and Negative Syndrome Scale (PANSS) total score and the Clinical Global Impression, Severity scale (CGI-S).

Results: 427 patients were randomized to lurasidone and 202 to risperidone with 147 (34\%) of lurasidone-treated and 89 (44\%) risperidone-treated patients completing 12 months of treatment. Rates for discontinuations due to adverse events and insufficient clinical response, respectively, were $17 \%$ and $7 \%$ for lurasidone, and $11 \%$ and $6 \%$ for risperidone. The 3 most frequent adverse events in the lurasidone group (vs. risperidone) were nausea (16.7\% vs. $10.9 \%)$, insomnia $(15.8 \%$ vs. $13.4 \%)$ and sedation $(14.6 \%$ vs. $13.9 \%)$; the 3 most frequent adverse events in the risperidone group (vs. lurasidone) were increased weight (19.8\% vs. $9.3 \%)$, somnolence $(17.8 \%$ vs. $13.6 \%)$ and headache $(14.9 \%$ vs. $10.0 \%)$. Using $>/=7 \%$ change from baseline as the threshold for clinically significant weight change, $7 \%$ of lurasidone-treated subjects experienced an increase compared with $14 \%$ of risperidone-treated subjects ( $\mathrm{NNH}-16,95 \%-\mathrm{CI},-9$ to -104 , for lurasidone vs. risperidone). Furthermore, $13 \%$ of lurasidone-treated subjects experienced a decrease compared with $6 \%$ of risperidone-treated subjects (NNH 15, 95\%-CI, 9 to 40, for lurasidone vs. risperidone). Treatment with lurasidone and risperidone, respectively, were both associated with LOCF-endpoint reductions in median change in cholesterol $(-3.0 \mathrm{vs} .-7.0 \mathrm{mg} / \mathrm{dL} ; \mathrm{p}=0.321)$ and triglycerides $(-3.5 \mathrm{vs} .-1.0 \mathrm{mg} / \mathrm{dL}$; $p=0.528)$. The median endpoint change in glucose was significantly different between lurasidone vs. risperidone $(-0.5$ vs. $+3.0 \mathrm{mg} / \mathrm{dL} ; \mathrm{p}=0.005)$; conversely, a greater increase in insulin was observed for risperidone vs lurasidone $(-0.05$ vs. $+1.25 \mathrm{mU} / \mathrm{L})$. Median endpoint change in prolactin was minimal for lurasidone and significantly different from risperidone (+0.1 vs. $+9.1 \mathrm{ng} / \mathrm{mL} ; \mathrm{p}<0.001)$. On an MMRM analysis, ls mean change from Baseline in PANSS total score was -4.7 for the lurasidone treatment group and -6.5 for the risperidone treatment group $(p=0.18)$; and ls mean change from Baseline in the CGI-S was the same (-0.4) for both treatment groups at month 12.

Conclusions: 12 months of once-daily treatment with lurasidone, flexibly dosed at $40-120 \mathrm{mg}$, was safe and well-tolerated with minimal effects on metabolic parameters. In contrast, treatment with risperidone was associated with significantly greater effects on weight, measures of glycemic control and prolactin, but not on lipid parameters.

\section{PS-N11}

Optimizing outcomes in psychopharmacology continuing medical education: measuring learning and attitudes that may predict knowledge translation into clinical practice

Neuroscience education institute

Objectives: Participants will be able to: 1) Understand and identify Kirkpatrick's levels of learning; 2) Understand the importance of participant-focused educational design; 3) Understand how to measure the extent to which a CME activity facilitates sustained knowledge translation into clinical practice

Methods: Optimizing Outcomes in Psychopharmacology Continuing Medical Education: Measuring Learning and Attitudes That May Predict Knowledge Translation Into Clinical Practice will describe how the presenting organization designs, implements, and measures outcomes for activities within the field of psychopharmacology.

Key Points: This poster presentation will examine how well CME is working in the field of psychopharmacology. It will describe Kirkpatrick's levels of learning and provide examples of participant-focused educational design along with illustrating the objectives with examples of pre- and posttest questions and case-based examples.

\section{PS-123}

Effect of Lurasidone on Weight and Metabolic Parameters: Results from Pooled Short-term Placebo-controlled and Longer-term Trials in Schizophrenia

Andrei Pikalov, MD, PhD; Jose 
Study Objectives: The aim of these analyses was to evaluate the safety of lurasidone treatment of patients with schizophrenia on weight and metabolic parameters.

Methods: The safety analysis of short-term treatment with lurasidone was based on pooled data from seven doubleblind, placebo-controlled trials, including 4 with active comparators, of subjects who met DSM-IV criteria for schizophrenia with an acute exacerbation. The analysis sample consisted of subjects treated with lurasidone (dose range, $20-160 \mathrm{mg}$, total $\mathrm{N}=1508)$; haloperidol $10 \mathrm{mg}(\mathrm{N}=72)$; olanzapine $15 \mathrm{mg}(\mathrm{N}=122)$; risperidone $4 \mathrm{mg}$ $(\mathrm{N}=65)$; quetiapine $\mathrm{XR}(\mathrm{N}=119)$; and placebo $(\mathrm{N}=708)$. Longer-term (6-months and longer) open-label treatment data were also available from 19 studies of lurasidone $(\mathrm{N}=2905$ lurasidone-treated subjects) in doses ranging from $40-120 \mathrm{mg} /$ day.

Results: During short-term treatment, the mean (SD) change in weight, in kg at LOCF-endpoint, was +0.43 (2.87) for lurasidone (pooled), +0.02 (3.11) for haloperidol, +4.15 (20.07) for olanzapine, +2.09 (3.34) for quetiapine-XR, +0.20 (2.47) for risperidone, and -0.02 (2.72) for placebo. The proportion of patients experiencing $\geqslant 7 \%$ weight gain was $3.3 \%$ for placebo, $4.2 \%$ for haloperidol, $4.8 \%$ for lurasidone, $6.2 \%$ for risperidone, $15.3 \%$ for quetiapine $\mathrm{XR}$, and $34.4 \%$ for olanzapine. During short-term treatment, median endpoint changes in lipids were as follows: triglycerides (mg/dL), -4.0 for lurasidone (pooled), -3.0 for haloperidol, +25.0 for olanzapine, +4.0 for risperidone, +9.5 for quetiapine $\mathrm{XR}$, and -6.0 for placebo; total cholesterol $(\mathrm{mg} / \mathrm{dL}),-5.0$ for lurasidone, -8.0 for haloperidol, +9.0 for olanzapine, +6.5 for risperidone, +6.0 for quetiapine $\mathrm{XR}$, and -5.0 for placebo; similar trends existed for changes in LDL. Median LOCF-endpoint change in glucose $(\mathrm{mg} / \mathrm{dL})$ were similar for combined lurasidone $(0.0)$ and placebo $(0.0)$, and somewhat higher for haloperidol $(+2.0)$, olanzapine $(+4.0)$, risperidone $(+3.0)$, and quetiapine XR (+3.0). Minimal-to-no changes were observed at Week 6 LOCF-endpoint in HbA1c. In the longerterm treatment sample, mean change in weight in completers of 12 months treatment with lurasidone was $-0.73 \mathrm{~kg}$ (combined lurasidone treatment group); median changes in metabolic parameters at Month $12 \mathrm{OC}$ were: $-2.0 \mathrm{mg} / \mathrm{dL}$ for total cholesterol and $-5.0 \mathrm{mg} / \mathrm{dL}$ for triglycerides.

Conclusions: In these pooled analyses of both short-term and longer-term treatment studies, treatment with lurasidone was associated with minimal increases in weight and BMI in short-term trials, and small decreases in weight and BMI in longer-term trials. Decreases in median total cholesterol and triglycerides were observed with both short-term and longer-term treatment with lurasidone. Treatment with lurasidone was not associated with clinically significant changes in glucose or HbA1c.

This study was funded by Sunovion Pharmaceuticals, Inc.

\section{PS-124}

Lurasidone in The Treatment Of Acute Schizophrenia: Results Of The Double-Blind, Placebo-Controlled, 6-Week Trial, PEARL 3

David T. Crandall, PhD; Antony Loebel, MD; Josephine Cucchiaro, PhD; Kaushik Sarma, MD; Jane $\mathrm{Xu}$, PhD; Jay Hsu, PhD; Amir H. Kalali, MD; Steven G. Potkin, MD

Study Objectives: The aim of this placebo- and active-controlled study was to evaluate the efficacy and safety of lurasidone $(80 \mathrm{mg} /$ day and $160 \mathrm{mg} /$ day) in patients with an acute exacerbation of schizophrenia.

Methods: Hospitalized patients who met DSM-IV criteria for schizophrenia with a PANSS total score $>80$ were randomized to 6-weeks of double-blind treatment with lurasidone $80 \mathrm{mg}(\mathrm{N}=125)$, lurasidone $160 \mathrm{mg}(\mathrm{N}=121)$, quetiapine XR $600 \mathrm{mg}(\mathrm{QXR} ; \mathrm{N}=120)$, or placebo $(\mathrm{N}=122)$, administered once-daily in the evening. A MMRM analysis was performed for the primary efficacy measure, the Positive and Negative Syndrome Scale (PANSS) total score, and the CGI-Severity score.

Results: Treatment with lurasidone for 6 weeks led to significantly greater endpoint improvement of the PANSS total score from baseline vs. placebo. This was true for both dosage groups: improvements from baseline to end of week 6 were -10.3 for placebo, -22.2 for lurasidone $80 \mathrm{mg}(\mathrm{P}<0.001)$ and -26.5 for lurasidone $160 \mathrm{mg}(\mathrm{P}<0.001)$. These results were mirrored by significantly greater CGI-S improvements from baseline to end of week 6 for both dosages of lurasidone vs. placebo. Mean CGI-S improvements were -0.9 for. placebo, -1.5 for $80 \mathrm{mg}$ (P $<0.001 \mathrm{vs}$. placebo) and -1.7 for $160 \mathrm{mg}(\mathrm{P}<0.001$ vs. placebo). Significant separation from placebo occurred by Day 4 for both lurasidone doses on the PANSS total score. QXR also produced significantly greater endpoint improvement than placebo on the PANSS total score (-27.8 vs. -10.3 ; P $<0.001)$ and the CGI-S (-1.7 vs. $-0.9 ; \mathrm{P}<0.001)$, confirming assay sensitivity. The following adverse events occurred with an incidence $\geqslant 5 \%$ and $\geqslant 2$-times placebo: akathisia (L80; L160), nausea (L80; L160), parkinsonism (L80; L160), dizziness (L160, QXR), somnolence (L160, QXR), constipation (QXR), dry mouth (QXR), increased weight (QXR), upper respiratory tract infection (QXR) and 
arthralgia (QXR). Treatment with lurasidone $80 \mathrm{mg}$ and $160 \mathrm{mg}$, respectively, was associated with a mean increase in weight that was not significantly different from placebo $(+0.6 \mathrm{~kg}$ and $+0.6 \mathrm{~kg}$ vs. $+0.1 \mathrm{~kg})$ while the mean increase in weight was significantly higher with quetiapine $\mathrm{XR}(+2.1 \mathrm{~kg} ; \mathrm{P}<0.001 \mathrm{vs}$. placebo). Total cholesterol and triglycerides were decreased at endpoint on both doses of lurasidone, but showed increases on quetiapine XR.

Conclusions: Lurasidone $80 \mathrm{mg}$ and $160 \mathrm{mg}$, administered once-daily in the evening, demonstrated superiority compared to placebo on the PANSS total score and the CGI-S. Assay sensitivity was confirmed by the active control, quetiapine XR. Lurasidone was well-tolerated, with no clinically significant dose-related increase in adverse events, despite treatment with a dose of $160 \mathrm{mg}$, which is above the recommended maximum dose of $80 \mathrm{mg} /$ day. Treatment with lurasidone was associated with minimal and generally non-significant changes in weight or metabolic parameters. Significant increases in weight and lipids were observed for quetiapine XR vs. placebo.

This study was funded by Sunovion Pharmaceuticals, Inc.

\author{
PS-125 \\ Long-Term Safety and Tolerability of Lurasidone in Patients With Schizophrenia: Results of a 6-Month, \\ Open-Label Extension Study \\ Stephen M. Stahl, MD, PhD; Josephine Cucchiaro, PhD; Doreen Simonelli, PhD; Joseph Severs, MS; \\ Barry Herman, MD, MMM; Antony Loebel, MD
}

Study Objectives: The aim of this study was to evaluate the safety and tolerability of lurasidone in the long-term treatment of schizophrenia, and to determine if improvement during acute double-blind (DB) treatment was sustained.

Methods: Patients who completed a 6-week, DB, placebo- and active-controlled trial evaluating the efficacy of lurasidone $40 \mathrm{mg}$ and $120 \mathrm{mg}$, and olanzapine $15 \mathrm{mg}$ (active control to confirm assay sensitivity) in acute exacerbation of schizophrenia were eligible to participate in a 6-month open-label extension (OLE) study in which patients received flexibly-dosed lurasidone $40-120 \mathrm{mg} /$ day. Safety and tolerability measures included adverse events (AEs), body weight, lipid profile, HbA1c, insulin, prolactin, and ECGs. Efficacy assessments included the Positive and Negative Symptoms of Schizophrenia Scale (PANSS) total score.

Results: The mean PANSS total score for all patients $(\mathrm{N}=246)$ who continued into the OLE decreased from 96.6 (at the baseline of the initial 6-week DB study) to 66.6 at the baseline of the 6-month OLE. Continued treatment during the OLE resulted in further improvement in the PANSS total score, with a mean (SD) change of -3.0 (16.3) on an LOCF endpoint analysis, and -8.7 (14.4) on an observed case analysis. During OLE treatment, two AEs occurred with an incidence $>10 \%$ : akathisia (13.0\%) and insomnia (11.0\%); $7.3 \%$ of patients reported experiencing a severe $\mathrm{AE}$, while $12.2 \%$ of patients discontinued due to an $\mathrm{AE}$. There were no clinically meaningful changes in vital signs, or laboratory and ECG parameters; one subject experienced $>60 \mathrm{msec}$ increase in QTcF, and no subject had a QTcF interval $>500$ msec. Patients who continued receiving lurasidone had no clinically meaningful changes from open-label baseline to endpoint in cholesterol $(-7.1 \mathrm{mg} / \mathrm{dL})$, LDL $(-2.6 \mathrm{mg} / \mathrm{dL})$, triglycerides $(-18.3 \mathrm{mg} / \mathrm{dL})$, insulin $(-2.4 \mathrm{mU} / \mathrm{L})$, or whole blood $\mathrm{HbA1c}(-0.06 \%)$. Prolactin, which had increased during the DB study $(+3.2$ $\mathrm{ng} / \mathrm{mL}$ on combined lurasidone; $+3.4 \mathrm{ng} / \mathrm{mL}$ on olanzapine), showed an overall median decrease $(-1.3 \mathrm{ng} / \mathrm{mL})$ during the OLE. Body weight and BMI remained relatively stable during the open-label extension, except for patients who had been randomized in the preceding acute DB study to olanzapine $15 \mathrm{mg}$. These patients experienced a mean (SD) reduction of $-1.8(4.9) \mathrm{kg}$ in weight after being switched to lurasidone in the OLE

Conclusions: During this 6-month, open-label extension study, flexibly dosed lurasidone (40-120 mg, daily) was well-tolerated in patients with schizophrenia. Lurasidone showed low potential for weight gain and dyslipidemia in patients treated for up 8 months (acute and extension study treatment, combined). PANSS total score reductions observed after 6-week acute DB treatment with lurasidone were sustained in this 6-month open-label extension study.

This study was funded by Sunovion Pharmaceuticals, Inc.

\title{
PS-126
}

The impact of methylphenidate on error monitoring and inhibitory control in children with attention-deficit hyperactivity disorder (ADHD)

Jonathan Lipszyc, MSc. 
Study Objectives: Impairment in error monitoring has been implicated in ADHD. We aimed to examine the effect of methylphenidate (MPH) on error monitoring in children with ADHD using the Stop Task and also sought to determine whether there is an association between the impact of MPH on error monitoring and inhibition.

Method: We included eleven children with ADHD, ranging in age from 7-12 years. This study used a randomized, double-blind, placebo-controlled, crossover design. Patients greater than $25 \mathrm{~kg}$ received $20 \mathrm{mg}$ of MPH, whereas those less than $25 \mathrm{~kg}$ received $15 \mathrm{mg}$.

Results: Children with ADHD on MPH had significantly shorter SSRTs, which refers to the latency of the inhibitory process, than ADHD children on placebo $(\mathrm{p}=0.009)$. However, there was no difference in post-error slowing, an index of error monitoring, between ADHD children on and off placebo.

Conclusions: There was no significant influence of MPH on post-error slowing as measured by the Stop Task in children with ADHD. It is possible that a higher dose of MPH is needed to improve post-error slowing. This study did confirm that $\mathrm{MPH}$ improves response inhibition, indicating a dissociation of inhibition and post-error adjustment, which supports the independence of post-error slowing and response inhibition.

This study was funded by Canadian Institutes of Health Research.

PS-127

Does Pharmacogenetic Testing in Psychiatric Populations Influence Clinician Treatment Selection and Confidence?

Jay Lombard, DO; Roy Perlis, PharmD; Bryce Kasuba, MA, MBA; Rachel Dicker, PharmD

Study Objectives: Impairment in error monitoring has been implicated in ADHD. We aimed to examine the effect of methylphenidate (MPH) on error monitoring in children with ADHD using the Stop Task and also sought to determine whether there is an association between the impact of $\mathrm{MPH}$ on error monitoring and inhibition.

Method: We included eleven children with ADHD, ranging in age from 7-12 years. This study used a randomized, double-blind, placebo-controlled, crossover design. Patients greater than $25 \mathrm{~kg}$ received $20 \mathrm{mg}$ of MPH, whereas those less than $25 \mathrm{~kg}$ received $15 \mathrm{mg}$.

Results: Children with ADHD on MPH had significantly shorter SSRTs, which refers to the latency of the inhibitory process, than ADHD children on placebo $(\mathrm{p}=0.009)$. However, there was no difference in post-error slowing, an index of error monitoring, between ADHD children on and off placebo.

Conclusions: There was no significant influence of $\mathrm{MPH}$ on post-error slowing as measured by the Stop Task in children with ADHD. It is possible that a higher dose of MPH is needed to improve post-error slowing. This study did confirm that $\mathrm{MPH}$ improves response inhibition, indicating a dissociation of inhibition and post-error adjustment, which supports the independence of post-error slowing and response inhibition.

This study was funded by Canadian Institutes of Health Research.

PS-128

Safety of Selegiline Transdermal System in Clinical Practice Analysis of Adverse Events From Post-marketing Exposures

Kimberly Portland, PhD; Ashwin Patkar, MD; Michael Thase, MD; J. Alexander Bodkin, MD

Study objective: Despite consistent evidence for efficacy, the clinical use of monoamine oxidase inhibitors (MAOIs) has declined because of safety concerns about food and drug interactions. Selegiline transdermal system (STS), US Food and Drug Administration (FDA) approved for major depressive disorder, was developed to overcome some limitations of oral MAOIs-in particular, dietary restrictions. Labeling for STS $6 \mathrm{mg} / 24 \mathrm{hr}$ requires no restrictions, while 9-mg/24 hr and 12-mg/24 hr doses necessitate dietary modifications. In clinical trials without dietary modifications, there were no reports of hypertensive crisis associated with STS. The objective of this analysis is to present the safety profile of STS in clinical practice after FDA approval, by analyzing post-marketing adverse events (AEs).

Method: We obtained de-identified data on AEs, regardless of causality, as collected by the manufacturer after the launch of STS in the United States. We carefully examined all reports of hypertensive crisis, suicide attempts, and STS overdoses to independently determine relation of the AE to STS. 
Results: From April 2006 to June 2010, a total of 3,155 AEs in 1,516 patients were reported (5.2\% of the total exposures $n=29,141)$, regardless of causality. The most frequently reported categories of AEs were general disorders $(n=1,037,3.6 \%)$, psychiatric disorders $(n=574 /, 2.0 \%)$, and CNS disorders $(n=382,1.3 \%)$. Altogether, $266(0.9 \%)$ reports were classified as serious AEs (SAEs)-psychiatric disorders $(n=71,26.7 \%)$, cardiac and vascular disorders $(n=44,16.5 \%)$, and CNS disorders $(n=40,15.0 \%)$ were most common. There were 13 self-reports of possible hypertensive crisis or hypertension, although objective clinical data were not submitted in any of these cases. There were $13(0.04 \%)$ drug-drug interactions reported, 5 of them classified as serious.

Conclusions: The most common AEs were application site reactions and insomnia. Very few reported a hypertensive event, and there were no objectively confirmed reports of hypertensive crisis with food at any STS dose. Therapeutic doses of STS appear to have a safety profile in clinical practice that is consistent with that observed in clinical trials. However, given the relatively modest exposure numbers, continued safety monitoring is recommended.

Supported by funding from Dey Pharma, L.P.

\section{PS-129}

Selegiline Transdermal System (STS) for Anxious Depression: A Post Hoc Analysis of 3 Randomized, Placebo-Controlled, Double-Blind Studies

Kimberly Portland, PhD; Donald Robinson

Study objective: Significant symptoms of anxiety are present in approximately half of patients with major depressive disorder (MDD). Previous studies indicate that patients with anxious depression may take longer to respond to antidepressant treatments and have a lower rate of response than patients with MDD who are lacking significant anxiety symptoms. This post hoc analysis seeks to compare the efficacy of selegiline transdermal system (STS) versus placebo in patients with anxious versus nonanxious major depression. STS has been shown to be an effective and well-tolerated acute and maintenance treatment for MDD. STS delivers sustained blood levels of monoamine oxidase inhibitor (MAOI) directly into systemic circulation, thereby avoiding the need for a tyraminerestricted diet at the $6 \mathrm{mg} / 24 \mathrm{hr}$ dose.

Method: Data from 3 short-term (one 6-week and two 8-week), randomized, double-blind, placebo-controlled clinical trials of STS were pooled for this analysis $(\mathrm{N}=742)$. Anxious depression was defined post hoc by a Hamilton Rating Scale for Depression (HAM-D) anxiety/somatization factor score $\geqslant 7$ as measured at baseline. Analysis of covariance (ANCOVA) and logistic regression modeling were used to test the effectiveness of STS versus placebo on the Montgomery-Åsberg Depression Rating Scale (MADRS) and the 28-item HAM-D at treatment endpoint.

Results: Two-thirds of the sample met the criteria cited above for "anxious depression" $(66.7 \%, \mathrm{n}=494)$ based on the HAM-D anxiety/somatization score. Both anxious and nonanxious depressed patients receiving STS showed significantly greater improvement at endpoint on MADRS and HAM-D total scores versus patients receiving placebo (all $\mathrm{P}<.05$ ). Remission rates as defined by endpoint MADRS were significantly better in both anxious and nonanxious patients treated with STS compared with placebo $(\mathrm{P}<.05)$, although remission based on the 28-item HAM-D did not reach statistical significance $(\mathrm{P}<.1)$.

Conclusions: STS is an effective treatment for patients with MDD presenting with anxious or nonanxious depression.

Supported by funding from Dey Pharma, L.P.

PS-130

Inattention as an important factor for quality of life in youth with epilepsy

Tatiana Falcone, MD; Sarah Matthys, MD; Prakash Kotagal, MD; Diana Lorenzo, MD

Abstract: We aimed to analyzed the relationship between quality of life and different factors that can impact the life of youth with epilepsy.

Using the knowledge project, records from outpatient visits 1500 epilepsy patients were reviewed, association between quality of life ratings and scores from the impact of Childhood Neurologic Disability Scale and the Liverpool Seizure Severity Scale.

The impact of inattention and behavior problems in the quality of life scale in youth with epilepsy was as severe as the impact of seizure severity and seizure frequency in the quality of life of this youth. 
Epilepsy treatment focus primarily on illness related factors, yet psychosocial and psychological factors tend to be overlooked. In this study we demonstrated how inattention can negatively impact the quality of life of children with epilepsy. Psychiatric comorbidities should be addressed sooner in patients with epilepsy to help them improve their quality of life.

\section{PS-131}

Onset of Action of Dextromethorphan/Quinidine for Treatment of Pseudobulbar Affect Demonstrated in a Randomized, Placebo-Controlled Trial-Authors: Adrian Hepner and Randall Kaye

Adrian Hepner, MD; Randall Kaye, MD

Study Objective: Pseudobulbar affect (PBA) is a neurologic disorder of emotional expression characterized by sudden, involuntary, and uncontrollable outbursts of inappropriate laughing or crying, which occurs secondary to neurologic diseases and other causes of brain injury such as multiple sclerosis (MS), amyotrophic lateral sclerosis (ALS), Parkinson's disease, Alzheimer's disease, stroke, and traumatic brain injury. PBA may cause embarrassment, social dysfunction, isolation, and impaired quality of life (QOL), independent of the underlying disorder. The only currently approved treatment for PBA is dextromethorphan/quinidine (DMQ), a combination product composed of the uncompetitive NMDA receptor antagonist/sigma-1 receptor agonist dextromethorphan, and low-dose quinidine, a potent and well-characterized CYP2D6 inhibitor. This analysis was conducted to evaluate the time to significant effect of DMQ for treatment of PBA.

Method: Patients with PBA secondary to MS or ALS were randomized to twice daily, double-blind treatment with DMQ 30/10 mg (DMQ-30), DMQ 20/10 mg (DMQ-20), or placebo, taken for 12 weeks. Patients recorded PBA episodes in daily diaries. The primary outcome was change in PBA episode rate during treatment. Time to onset of action, predefined as first occurrence of a 30\% decrease from baseline in PBA episodes, was an additional prespecified outcome.

Results: In total, 326 patients were randomized to DMQ-30 ( $n=110)$, DMQ-20 ( $n=107)$, or placebo $(n=109)$. The mean (SD) age was $51.4 \pm 11.4$ years, and $13.5 \%$ of patients were $\geqslant 65$ years-old. By Week 1 , significantly more patients in the DMQ-30 $(74.8 \% ; P=0.01)$ and DMQ-20 $(73.7 \% ; P=0.02)$ groups met onset criteria compared with placebo $(57.3 \%)$. However, at subsequent timepoints, progressively greater percentages in all groups met onset criteria, reaching $100 \%$ by week 12 and indicating that the prespecified onset criterion was insufficiently stringent. A post-hoc analysis of percent change in PBA episodes by week showed that by week 1, PBA episodes decreased by $47 \%$ (DMQ-30; $P=0.004)$, and 50\% (DMQ-20; $P=0.001)$ vs $23 \%$ (placebo). The differences in both DMQ groups remained significant vs placebo at all subsequent visits.

Conclusion: DMQ-30 and DMQ-20 demonstrated a significant decrease in PBA episodes by week 1 of treatment.

This analysis was supported by Avanir Pharmaceuticals, Inc.

\section{PS-132}

Competitive Binding of Dextromethorphan to Selective Brain Receptor Sites in Rat Tissue-Authors: Linda Werling and Laura Pope

Linda L. Werling, PhD; Laura E. Pope, PhD

Study Objective: Dextromethorphan (DM) is an uncompetitive NMDA receptor antagonist and a sigma-1 receptor agonist. Through these interactions it regulates excitatory glutamatergic pathways. DM also has also demonstrated affinity at serotonin transporters (SERT) (Meoni et al, 1997). This experimental study was conducted to assess the competitive binding of DM and DX, as well as 3 psychoactive agents: memantine (an uncompetitive NMDA receptor antagonist), amitriptyline (a tricyclic antidepressant), and fluoxetine (a serotonin reuptake inhibitor), to brain receptor sites.

Background: DM modulates excessive glutamate neurotransmission and has therefore been proposed as a potential treatment for a wide variety of neurologic disorders, including acute and chronic pain, neuroprotection and emotional lability. However, its extensive and rapid first-pass metabolism when administered alone results in very low or undetectable plasma concentrations.

Because of this rapid metabolism to its metabolite dextrorphan (DX) through the CYP 2D6 enzyme system, a combination with low-dose quinidine, a potent CYP 2D6 inhibitor, was developed to significantly slow the DM first-pass metabolism, resulting in increased bioavailability and potential for therapeutic usefulness. 
The combination of DM and Q (DMQ) has been successfully evaluated in RCT for the treatment of pseudobulbar affect (PBA). PBA is a distinct neurologic disorder of emotional expression, occurring secondary to a variety of neurologic diseases and brain injury; PBA is clinically characterized by involuntary, sudden and uncontrollable outburst of laughing and/or crying that are often excessive or inappropriate to the contextual stimulus, and may be incongruent with the patient's mood.

Methods: Frozen brains from male Sprague-Dawley Rats were thawed, dissected, and homogenized. Radioligand competitive binding studies were conducted for memantine, amitriptyline, fluoxetine, DX, and DM at 26 target sites, including sigma-1 receptors, serotonin transporter (SERT), alpha-2 adrenoceptors, phencyclidine (PCP) receptors, and $5 \mathrm{HT}_{1 \mathrm{~B} / \mathrm{D}}$.

Results: DM competed for sigma-1 and SERT in a concentration-dependent manner, and also showed competition for alpha-2 adrenoceptors and $5 \mathrm{HT}_{1 \mathrm{~B} / \mathrm{D}}$ receptors. DM bound with the highest affinity to SERT followed by sigma1 receptors. DM showed competition for the lowest number of other receptor sites. DX had a higher affinity for PCP binding sites than did DM. Amitriptyline and fluoxetine competed at sigma-1 receptors with slightly lower affinities than DM and bound multiple other nontarget sites. Memantine showed no competition for sigma-1 receptors or SERT at the concentration tested.

Conclusion: The mechanism of DMQ in reducing PBA episodes is unknown. The binding profile of DM was different from that of DX, memantine, fluoxetine and amitriptyline, with lower binding to potential nontarget sites. DM binds with highest affinity to SERT and sigma-1 receptors; it weakly binds to the PCP site, and has some affinity at $5-\mathrm{HT}_{1 \mathrm{~B} / \mathrm{D}}$ and $\boldsymbol{\alpha} 2$ sites. One or more of these interactions may contribute to its efficacy in PBA and may suggest further therapeutic areas for clinical exploration.

This study was supported by Avanir Pharmaceuticals, Inc.

PS-133

Acute and subchronic Lu Aa21004 Induces Monoamine Release through a Mechanism Involving Multiple Serotonergic Receptors

Ebert Bjarke, PhD, DSc; Alan Pehrson, PhD; Connie Sanchez, PhD, DSc; Thomas Cremers, PhD

\begin{abstract}
The multimodal antidepressant Lu AA21004 is a 5-HT3 and 5-HT7 receptor antagonist, 5-HT1A receptor agonist, 5-HT1B receptor partial agonist and inhibitor of the 5-HT transporter. Acute microdialysis studies in rats have demonstrated a dose-dependent increase in extracellular brain serotonin (5-HT), norepinephrine (NE), and dopamine (DA) levels [1]. We examined the effect of Lu AA21004 under steady-state conditions and related the neurotransmitter output to SERT occupancy.
\end{abstract}

Methods: Male Wistar rats were anesthetized with isoflurane and implanted with osmotic minipumps, which delivered vehicle, 19.0 , or $28.0 \mathrm{mg} / \mathrm{kg} /$ day of $\mathrm{Lu}$ AA21004, or $7.5 \mathrm{mg} / \mathrm{kg} /$ day escitalopram. After 3 days, microdialysis probes were stereotaxically implanted into each rat. The effects of an acute challenge with $10.0 \mathrm{mg} /$ $\mathrm{kg}$ Lu AA21004 were also assessed. Finally, 5-HT transporter (SERT) occupancy was estimated in satellite animals for each treatment group using ex vivo autoradiography.

Results: Lu AA21004 produced a statistically significant increase in extracellular 5-HT, NE, and DA levels at SERT occupancies corresponding to 88 and 98\%. Moreover, Lu AA21004 elevated basal 5-HT release to a significantly greater extent than $7.5 \mathrm{mg} / \mathrm{kg}$ / day escitalopram, despite similar levels of SERT occupancy (92\%). Acute challenge with $10.0 \mathrm{mg} / \mathrm{kg}$ Lu AA21004 in rats that received 3 days of vehicle caused significant increases in 5-HT release, while no additive effect was observed in rats that received either dose of Lu AA21004 for 3 days.

Conclusions: These data support the hypothesis that Lu AA21004 exerts its effects by modulating several serotonergic targets. This multimodal action may translate into unique effects in the clinic. 